\title{
Setor de conservas da região de Pelotas (RS): mudanças na produção e conservadorismo nas relações de trabalho
}

\section{Sector of canned goods in the region of Pelotas (RS): changes in production and conservatism in labor relations}

\author{
Laura Senna Ferreira \\ Doutoranda em Ciências Humanas (Universidade Federal do Rio de Janeiro - UFRJ) \\ laurasennafe@hotmail.com
}

\begin{abstract}
Resumo
A maioria das fábricas do setor conserveiro da região de Pelotas, no Rio Grande do Sul, foi fechada a partir de 1990, o que representou um intenso desemprego na região, essencialmente, para as mulheres, maior parte dos empregados no ramo. A reestruturação empresarial fragilizou a posição de trabalhadores e sindicatos do setor, e as formas coletivas de organização se viram restritas. A partir das entrevistas narrativas e história oral, buscou-se compreender porque o ritmo das transformações produtivas, em termos tecnológicos, não foi acompanhado por alterações em determinadas relações de trabalho. Procurou-se identificar os elementos e motivos da intensificação do desemprego, informalidade e precarização narrados pelos trabalhadores, bem como, questionou-se as razões para a permanência do predomínio da mão-de-obra feminina e da sazonalidade da produção.
\end{abstract}

Palavras-chave: Reestruturação produtiva. Relações de trabalho. Conservadorismo. Desemprego. Indústria conserveira.

\begin{abstract}
Most factories in the sector of canned goods in the region of Pelotas, in Rio Grande do Sul, have been closed since 1990, representing a heavy unemployment in the region, mainly for women, most employees in the business. The business reorganization weakened the position of workers and unions in the sector, and collective forms of organization found themselves restricted. From the interviews and oral history narratives, we sought to understand why the pace of changes in production, in technological terms, was not accompanied by changes in working relations. We sought to identify the elements and motifs from increased unemployment, informality and precariousness narrated by workers and, questioned whether the reasons for continuing predominance of manpower female and seasonality of production.
\end{abstract}

Keywords: Restructuring of production. Labor relations. Conservatism. Unemployment. Sector of canned goods.

Originais recebidos em: 19/10/2010

Aceito da publicação em:. 08/03/2011

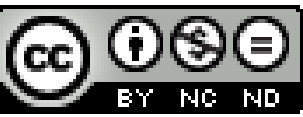

Este trabalho está licenciado sob uma Licença Creative Commons Atribuição-Uso Não-Comercial-Vedada a criação de obras derivadas 3.0 Unported License. 


\section{Introdução}

A região de Pelotas, no Rio Grande do $\mathrm{Sul}^{1}$, é historicamente uma zona de produção de alimentos, começando pelo charque, que foi a primeira economia da região, passando posteriormente para o arroz, beneficiamento da soja e industrialização de frutas. A indústria de conservas de hortaliças e frutas surgiu em fins do século XIX e inícios do século $\mathrm{XX}$, quando se formaram várias pequenas fábricas junto às propriedades de produtores rurais.

Até os anos 1970, o ramo era composto, basicamente, por pequenos empreendimentos artesanais. A partir desse período ocorre a construção do Distrito Industrial e a constituição de grandes indústrias, tornando a região a maior produtora de compotas de pêssego do Brasil.

A fabricação de doces, conservas de diferentes frutas e legumes se tornou a principal atividade econômica de Pelotas e municípios vizinhos até fins dos anos 1980 . Porém, ao longo da década de 1990, a maioria das empresas, não suportando a concorrência dos empreendimentos mais avançados em termos de produtividade, encerra suas atividades. As que continuaram em funcionamento se reestruturaram e, hoje, atingem uma produtividade sem precedentes no setor, sendo responsáveis por $98 \%$ das compotas de pêssego produzidas no mercado brasileiro ${ }^{2}$.

Ao fechamento de quase trinta fábricas a partir de fins de 1980, seguiu-se uma grande redução da força de trabalho empregada. No espaço de trabalho, a realidade de efetivos e safristas que, no passado, contavam com a alternativa de mudar de empresa caso achassem necessário, foi alterada. Diante desse cenário de restrições para o emprego, a mobilização coletiva dos trabalhadores passa por grandes dificuldades.

No presente artigo procura-se, num primeiro momento, indicar a metodologia empregada durante a pesquisa. Num segundo instante, analisam-se aspectos da trajetória dessa indústria e as relações que se estabelecem com as instituições que denotam envolvimento relevante nessa cadeia. A seguir, observam-se as mudanças e continuidades inauguradas pelos anos 1990, relacionando-as ao mundo do trabalho. Por fim, almeja-se entender a forma que os trabalhadores narram suas experiências e se posicionam frente ao novo contexto.

\footnotetext{
1 A Região Sul do Rio Grande do Sul é hoje composta por 22 municípios, comportando 8,13\% da população do RS (Censo 2000). Pelotas é a maior cidade da região.

${ }^{2}$ Dados: Sindicato dos Doces e Conservas Alimentícias de Pelotas (SINDOCOPEL).
} 


\section{Metodologia}

A amostra da pesquisa considerada neste artigo se baseou em uma representatividade qualitativa, procurando preservar a heterogeneidade dos sujeitos analisados. Nessa perspectiva, as entrevistas cessaram quando se percebeu que os relatos não estavam acrescentando nada de novo ${ }^{3}$

Utilizou-se como fonte primária entrevistas narrativas e história oral, e de forma secundária, jornais, laudos médicos, documentos governamentais, livro de denúncias do sindicato dos trabalhadores, arquivos do sindicato patronal e observação direta nas empresas.

Foram entrevistados membros de instituições em interação com o setor, tais como EMBRAPA (Empresa Brasileira de Pesquisa Agropecuária), EMATER (Empresa de Assistência Técnica e Extensão Rural), SEBRAE (Serviço de Apoio as Micro e Pequenas Empresas), Sindicato dos Trabalhadores Rurais, Cooperativa de Fruticultores (COOPERFRUTIS) e Cadeia Agroindustrial de Frutas e Hortaliças (CAFH).

Exceto essas entrevistas estruturadas, cujo foco era mais no sentido de obter informações e dados, as demais, junto a trabalhadores e sindicalistas (sindicato patronal e sindicato dos trabalhadores), foram "entrevistas narrativas" e "história oral". No total foram realizadas 32 entrevistas: 7 com empresários, 11 com trabalhadores, 4 com sindicalistas e 10 com representantes de entidades vinculadas ao setor.

Tanto no momento da pesquisa documental, quanto nas entrevistas, priorizou-se os acontecimentos que se deram a partir dos anos 1990, momento identificado como um marco dos processos de reestruturação da produção e do trabalho nesse e em outros setores.

A narrativa adotada como recurso metodológico se compõe a partir de uma entrevista não estruturada, na qual os acontecimentos são reconstruídos a partir da perspectiva do informante. Os relatos individuais, devido ao discurso do sujeito estar relacionado à determinada realidade social, colabora para construção de trajetórias coletivas (Bauer, 2002). O interesse do pesquisador está em captar aquilo que ultrapassa o caráter particular do que é transmitido (Queiroz, 1988).

A perspectiva da narrativa considera as "vozes" dos sujeitos, baseando-se nos detalhes das suas próprias versões e percepções dos eventos. Através dela, pode-se

\footnotetext{
${ }^{3}$ Esse artigo se baseou numa pesquisa mais ampla e aprofundada (Ferreira, 2008).
} 
"ganhar acesso à heterogeneidade dos percursos (dos atores), muito dos quais se perdem para bases de dados estatísticos" (Gomes, 2002, p. 131). Entre as estratégias qualitativas de coleta de material, o relato narrativo, na forma, por exemplo, de história oral, possibilita o acesso à conteúdo e representações que expressam os valores do próprio narrador ou de outros protagonistas daquelas vivências (Queiroz, 1988).

A investigação considerada procurou abordar os elos mais significativos da cadeia de conservas da Região Sul com dedicação especial a entender a relação entre a indústria e os trabalhadores. Um dos objetivos cruciais foi compreender a forma como o setor se insere no movimento de reestruturação produtiva a partir dos anos 1990. Nesse sentido, considerou-se narrativas e memórias acerca do passado e das situações contemporâneas, principalmente, aquelas que se referem à maneira como os trabalhadores percebem, assimilam e recusam as velhas e novas práticas empresariais.

\section{O trabalho no cerne das transformações do setor de conservas da região de Pelotas (RS): Discussão e resultados}

\section{Reestruturação produtiva do setor conserveiro}

O cenário de fábricas artesanais de conservas, que operavam na região com recursos próprios e baixo nível tecnológico, começa a se transformar nos anos 1970. A Cica, uma empresa familiar como as que existiam no local, foi a primeira grande indústria do ramo alimentício da região. A partir dessa empresa, o município montou seu parque industrial (Tavares, 2000).

Dessa década em diante, o setor aumenta sua produtividade, diversifica a produção, expande empresas e atrai empresários de outros Estados. A maioria dos autores (Grando, 1989; Tavares, 2000; Garcia, 2002) e dos entrevistados (empresários e membros das instituições) indicam a capacidade de expansão dos investimentos empresariais e a existência de apoio em termos de políticas públicas.

Contudo, a partir de 1980, as narrativas e documentos começam a apontar um cenário de "crise" em uma tentativa de explicar o fechamento da maioria das fábricas do setor nesses anos. Das 100 empresas que se registrava em 1950, havia somente $40 \mathrm{em}$ 1980 e 18 nos fins do mesmo decênio. No final da primeira década de 2000, existiam apenas 12 fábricas de conservas na região de Pelotas. 
Apesar das suas diferentes trajetórias, todas elas continuam compostas por uma força de trabalho predominantemente feminina, são familiares ${ }^{4}$, vinculadas à produção agrícola e sazonais, atuando, principalmente, na safra do pêssego, de novembro a $\operatorname{março~}^{5}$.

Segundo o modelo de análise proposto por Harvey (1992), as empresas, de modo geral, procuraram superar a "crise" da década de 1980 flexibilizando produtos e processos, a fim de confrontar a rigidez do fordismo. No entanto, regimes fordistas, artesanais e flexíveis convivem, permitindo, dessa maneira, aos capitalistas "escolherem" (Harvey, 1992, p. 175) o que lhes parece mais conveniente.

No caso do setor conserveiro, não se pode falar de uma substituição nem de uma permanência exclusiva do fordismo-taylorismo. Nossa pesquisa constatou que ao mesmo tempo em que essas empresas mantêm certas características do modelo, tais como linha de produção com esteiras, sistema de estoques e decisões centralizadas, adotam também inovações. Observa-se o uso de tecnologias automatizadas, o sistema de gestão com ênfase na "qualidade total", as Boas Práticas de Fabricação (BPF) ${ }^{6}$, as pesquisas genéticas desenvolvidas pela EMBRAPA etc., "mesclando" (Antunes, 2006, p. 19), assim, velhas e novas formações.

Somam-se a isso, aspectos elementares do toyotismo, como a necessidade de aumentar a produtividade sem ampliar a quantidade de bens produzidos, investimento em organização, tecnologia e enxugamento de custos com força de trabalho, em um mercado que não se expande (Coriat, 1994, p. 148). Viu-se que, se o consumo de compotas estagnou nas últimas décadas, a produtividade dessas empresas cresceu sem precedentes. Na década de 1980, 40 empresas produziram cerca de 50 milhões de latas de $\operatorname{compotas}^{7}$, quantidade obtida hoje com 12 fábricas em funcionamento.

A automação e a concentração empresarial, de acordo com Mattoso (1995), são elementos que, combinados, representam uma novidade dos tempos de reestruturação produtiva. Essa perspectiva é exatamente a que se encontra no setor conserveiro. Uma única das 12 empresas, com maquinários de ponta, concentra $78 \%$ do faturamento de todo setor. Tal concentração, que remete a "livre concorrência para esferas nebulosa dos

\footnotetext{
${ }^{4}$ A propriedade das empresas pertence a uma família, mas as funções administrativas e de gestão são executadas, na maioria dos casos, por gestores contratados. Sobre uma definição mais detalhada de empresa familiar Cf. Gersick (1998).

${ }^{5} \mathrm{Na}$ entressafra do pêssego, algumas dessas fábricas (a minoria) industrializam morango, abacaxi, cereja, figo, ervilha, milho, entre outros.

${ }^{6}$ Sobre BPF Cf. SEBRAE (1999).

${ }^{7}$ Em 1980 havia 40 fábricas, 4.300 efetivos e 17.000 safristas. Fonte: SINDOCOPEL.
} 
mitos" (Bernardo, 2004, p. 120), demonstra a diferente composição e correlação de forças entre as empresas, a "luta entre irmãos inimigos" (Cattani, 1995, p. 15).

Dentro da lógica do "enxugamento" e da busca por lucratividade, elas evitam tudo que consideram porosidades. Nesse movimento de racionalização que, segundo Castro et al (1998), ocorreu em toda América Latina, muitas empresas aumentaram sua participação nos mercados sem estender suas atividades produtivas. No caso do setor conserveiro, fábricas menores, em um sistema de subcontratação (SEBRAE, 1992), produzem para outras uma parte ou todo o produto, enquanto a empresa contratante agrega apenas a marca.

As fábricas de conservas adotaram uma série de mudanças tecnológicas nos últimos anos: descaroçadeira automática, recravadeira para fechamento de lata, rotuladeira que substituiu o processo manual de colagem, enchedeira automática para por calda nas latas, bem como outras tecnologias de processo com alta capacidade produtiva e redução de custos com a força de trabalho. Junto a isso, em termos organizacionais, as Boas Práticas de Fabricação e os cuidados com tratamento de efluentes, visando responder às exigências de "responsabilidade ambiental", têm sido uma preocupação do segmento.

No que se refere às políticas públicas, verifica-se incentivos governamentais à modernização, como foi o $\operatorname{PRIM}^{8}$ e a redução de Imposto Sobre Circulação de Mercadorias e Prestação de Serviços (ICMS) para realização de marketing institucional. Também há o Arranjo Produtivo Local (APL) - Conservas ${ }^{9}$ que conta com recursos do Governo Federal e do Estado e linhas de créditos especiais, como no caso da Linha Especial de Crédito para Indústria (LEC) - Pêssego do Banco do Brasil ${ }^{10}$ que se soma ao Programa de Geração de Emprego e Renda - Banco do Brasil (PROGER) ${ }^{11}$ e ao Programa Nacional da Agricultura Familiar (PRONAF), que contemplam industriais e produtores do setor.

Quanto à organização política, a CAFH (Associação Gaúcha da Cadeia Agroindustrial de Frutas e Hortaliças) criada em 1996, da qual fazem parte os elos relevantes da cadeia, obteve uma série de vantagens competitivas para o ramo.

\footnotetext{
${ }^{8}$ A lei do PRIM, criada pelo governador Britto (PMDB) em 1996, estipulava um retorno de $75 \%$ do ICMS para o setor. No Art. $8^{\circ} \mathrm{II}$, consta que o setor, para receber os incentivos, deveria estar comprometido em gerar emprego. Fonte: Assembléia Legislativa. Disponível em: <www.al.rs.gov.br>.

${ }^{9}$ O APL - Conservas trata-se de um projeto lançado pelo Governo Federal, implantado no RS durante o governo de Olívio Dutra-PT (SEBRAE, 2006).

${ }^{10}$ Linha Especial de Crédito para Indústria junto ao Banco do Brasil a 8,75\% de juros ao ano.

${ }^{11}$ PROGER é um financiamento Federal para aquisição de maquinário.
} 
Tais inovações tecnológicas, financeiras e institucionais indicam, como destaca Ianni (2004), que nos anos 1990 os diferentes segmentos produtivos vão passar por mudanças que os integram ao movimento geral de globalização sem que, com isso, deixem de manter suas especificidades.

Nesse sentido, entende-se que, por mais que as explicações sobre a chamada "crise" do setor conserveiro adotem uma argumentação no sentido de atribuir à mentalidade empresarial conservadora local o fechamento da maioria dos empreendimentos, não se pode deixar de situar essa "crise" entre as transformações globais que ocorreram nos últimos anos.

No caso do setor conseveiro, a concorrência com os produtos estrangeiros (como os gregos e argentinos), a assimilação de tecnologias fabricadas por transnacionais (como a descaroçadeira), a participação em feiras internacionais (a exemplo de Anuga, na Alemanha), a incorporação de pesquisas (como os melhoramentos genéticos da EMBRAPA), a adoção de novos modelos organizacionais (como a BPF, o APL e a rastreabilidade), colocam o setor na órbita internacional.

A visão de que os empresários do setor possuem uma "mentalidade conservadora" e pouco empreendedora (Decker, 2006), parte do suposto de que as causas para o fechamento da maior parte das fábricas devem ser buscadas na mentalidade e no comportamento "menos capitalista" (Técnico da EMATER, relato oral) dos empresários locais, "gente que nasceu pra ser empregado" (Pesquisador da EMBRAPA, relato oral).

Se os empresários das conservas investem em terras e imóveis, em vez de expandir ainda mais suas fábricas, essa "cultura empresarial”, para usar uma expressão de Kirschner (2006), indica tão somente um jeito particular de ser capitalista. Além disso, as grandes mudanças que se verificam nos processos produtivos fazem com que seja difícil negar as posturas de racionalização empresarial adotadas no setor.

Como sugere Ianni (2004), nos mais variados países e localidades, ao lado das diferentes culturas, padrões, valores e contingências históricas, encontra-se um comportamento empresarial que, embora adotando distintas estratégias, ritmos e intensidade, está em conformidade com as exigências da produtividade, competitividade e lucratividade.

Assim, não há motivo para se considerar que os empresários das conservas seriam “menos capitalistas”, mas apenas que estão agindo de uma maneira específica. Quando se observa que a produtividade cresceu incomparavelmente em relação a outras 
épocas, torna-se pouco consistente dizer que o "setor produz do mesmo jeito que há 30, 40 anos atrás" (Supervisora do SEBRAE, relato oral).

Os fomentadores e pesquisadores desse ramo minimizam a importância das transformações porque, para a maioria deles, a esfera do trabalho permanece na invisibilidade.

Nesse sentido, entende-se ser necessário rever a argumentação sobre o suposto “conservadorismo" do setor, e fazê-lo, reconhecer que, se existe algum comportamento conservador por parte dos empresários locais, ele diz respeito muito mais ao mundo do trabalho do que às estruturas produtivas dos empreendimentos.

\section{Reestruturação produtiva: novas/velhas práticas relacionadas aos trabalhadores}

A análise do setor conserveiro da Região Sul se torna mais rica quando feita de forma abrangente, incluindo os diferentes elos da Cadeia. A pertinência de estudar determinado ramo produtivo, procurando suas várias interfaces, é colocada por Abramo (1999, p. 6) ao defender a importância da análise da cadeia produtiva com foco no trabalho, evitando que esse se obscureça no deslocamento para a ênfase na empresa.

Na concepção de Harvey (1992), que focaliza, essencialmente, o trabalho, as empresas respondem à crise de acumulação de 1980, apelando para o desemprego, trabalho parcial, temporário, controle e repressão.

No setor estudado, tais características já estavam presentes antes mesmo de se tornarem uma questão ampliada a vários ramos produtivos no Brasil. No entanto, desde os anos 1990, o segmento tem se dedicado mais à industrialização exclusiva do pêssego. Entende-se que tal opção está vinculada ao refluxo das demais atividades ${ }^{12}$, mas também, à possibilidade de contar com uma maior flexibilidade do mercado de trabalho. Produzindo apenas na safra, lançam mão de contratos de poucos meses, demitem e recontratam sem aviso prévio, férias e seguro desemprego.

Os trabalhadores recebem o menor piso da categoria da alimentação, trabalhando num ritmo acelerado e com altas jornadas de trabalho, sem que se faça necessário grandes investimentos em formas de organização. A precariedade das condições é tolerada em função de ser um emprego temporário, "a gente agüenta porque é safra" (Safrista, relato oral). Assim, se a sazonalidade é uma decorrência da produção agrícola

\footnotetext{
12 Antes da década de 1990, a maioria das empresas, na entressafra do pêssego, industrializava figo, morango, ameixa, cereja, abacaxi, aspargo, ervilha, milho, entre outros.
} 
e do encerramento de algumas linhas de produção (outras frutas e hortaliças que eram processadas), também é uma escolha política empresarial.

Em relação às questões levantadas por Harvey (1992), pode-se afirmar que, também nas conservas, houve uma resposta à "crise" que flexibilizou ainda mais as relações de trabalho, mas sem se verificar, como coloca o autor, uma preocupação gestorial com o engajamento dos trabalhadores. No setor, ocorre uma cooperação "forçada", como se viu nas situações repressivas, indo de xingamentos à violência física (entrevistas com trabalhadores), remetendo, dessa forma, aos métodos autoritários próprios de uma fábrica fordista que priorizam o "controle coercitivo" (Tragtenberg, 1985).

O recente aumento do controle ${ }^{13}$ e da produtividade não teve como contraponto maiores concessões aos empregados. Pelo contrário, elementos singelos, porém valorizados por eles, como as doações de frutas, compotas e cestas de final de ano, bem como as festas promovidas pelas empresas, foram reduzidos ou deixaram de existir. Sem contar que, em termos de direito, o auxílio-creche, por exemplo, foi uma das cláusulas perdidas no dissídio coletivo, assim como, em várias das empresas, o direito à insalubridade, mesmo quando, como indicaram sindicalistas e trabalhadores, as condições de trabalho não foram alteradas ${ }^{14}$

Nas conservas, as mobilizações coletivas sempre foram consideradas menos expressivas quando comparadas a outras categorias representadas pelo Sindicato dos Trabalhadores das Indústrias e Cooperativas da Alimentação (STICAP). Por serem safristas e uma categoria composta, predominantemente, por mulheres, os sindicalistas avaliam que são mais difíceis de serem organizadas, pois, a maioria delas, terminada a safra, afasta-se totalmente do sindicato. Além disso, o envolvimento com as atividades domésticas reduz a possibilidade de interação.

No entanto, as lutas cotidianas são formas comuns de manifestação desde os anos 1970. As sabotagens como, por exemplo, máquinas estragadas propositalmente, frutas colocadas fora, parafusos postos dentro das latas, dormirem escondidos nos banheiros, fingir desmaios ou dar "graças a Deus quando uma máquina estraga" (Safrista, relato oral) ${ }^{15}$ criavam e ainda criam problemas para as empresas. Como a

\footnotetext{
${ }^{13}$ A título de exemplo, nos últimos anos, as fábricas adotaram um sistema de crachás eletrônicos para regulação do tempo de permanência dos trabalhadores no banheiro.

${ }^{14}$ Cf. Convenções coletivas de 1999 a 2006.

15 Essas e outras situações semelhantes foram narradas por trabalhadores e industriais durante as entrevistas.
} 
forma de produção no setor ainda tem muitas características semelhantes ao modelo taylorista-fordista, as formas de conflito, em alguns momentos, assumem semelhanças com as práticas antagônicas travadas pelos trabalhadores nos anos 1970 (Maroni, 1982).

Conforme Antunes (2006), no início dos anos 1990 as empresas responderam à concorrência internacional, aos avanços do "novo sindicalismo" e aos conflitos no local de trabalho, reestruturando a produção a partir da redução de custos com força de trabalho e busca por maior produtividade.

No setor de conservas não foi diferente. Essa indústria chegou a empregar em torno de 17.000 mil pessoas na década de 1980, hoje, emprega em torno de 3.000 mil trabalhadores. É uma grande redução de custos com a força de trabalho sem que se tenha reduzido a produtividade. Pelo contrário, o máximo que se produziu na década de 1980, com 40 empresas em funcionamento, foram 48 milhões de latas de compotas de pêssego, no final da primeira década de 2000, 12 empresas, produzem mais de 50 milhões por safra ${ }^{16}$

Todavia, os empresários do setor conserveiro, no sentido que indica Bernardo (2004), não puderam responder às rebeldias dos trabalhadores desregulamentando a esfera do trabalho muito além do que estava. Essa já era instável e informalizada. O que puderam fazer foi intensificar esses aspectos, apoiando-se no intenso desemprego que colocou boa parte dos trabalhadores numa condição de medo de perder a ocupação.

O setor cresceu e se organizou constituído por uma força de trabalho predominantemente sazonal, por moradores da periferia da cidade ou do interior rural, facilmente demitidos e recontratados. Porém, anteriormente, quando submetidos a 16 horas de trabalho, conforme indicam sindicalistas e trabalhadores tinham maior margem de manobra. Era comum pedirem as contas e tentarem emprego em outra fábrica. Tal possibilidade se tornou mais restrita nos últimos tempos, agravando a realidade tanto dos trabalhadores efetivos quanto dos safristas.

A degradação generalizada dos salários e proteções, segundo Hirata (1998a), atinge mais as mulheres, frequentemente empregadas em trabalho temporário e em tempo parcial, em nome da conciliação do emprego e atividades domésticas. Da mesma maneira, os menores salários recebidos são justificados em função dos seus ganhos

\footnotetext{
${ }^{16}$ Essa questão pode ser percebida analisando alguns dados: na safra de 1980/81 eram 40 fábricas que contratavam 4.300 efetivos e 17.000 safristas, produzindo 48 milhões de latas de pêssego. Em 1999/00 eram 18 fábricas com 1.200 efetivos e 5.100 safristas que produziam 50 milhões de latas. Já na safra de 2000/01, as 16 empresas da região empregavam 309 efetivos e 2.988 safristas, e produziam 50 milhões de latas. Fonte: SINDOCOPEL.
} 
serem apenas complementares à renda familiar. Levando em conta que o setor investigado sempre foi composto, predominantemente, por força de trabalho feminino, suas características de gênero, como os cuidados com os filhos e as atividades da casa, tenderam a fazer delas, como indica Leite (2004) em relação àquelas que trabalham a domicílio no setor têxtil, uma força de trabalho "especialmente disponível à atividade sazonal".

$\mathrm{Na}$ concepção de Hirata (1998b), as diferenças entre os sexos acabam atravessando o espaço da empresa. Nesse sentido, tanto nas entrevistas, quanto nas consultas documentais, percebe-se a presença de assédio, “cantadas”, favorecimentos ou desfavorecimentos de algumas trabalhadoras em função das relações que mantém com as chefias, chegando ao extremo de haver denúncia de estupro ${ }^{17} \mathrm{Na}$ indústria conserveira, indo ao encontro desse componente extra-fabril, embora mais de $90 \%$ do setor seja constituído por mulheres, as chefias são predominantemente homens.

Conforme Toledo (1997), nem sempre a mudança técnica vem acompanhada de transformações profundas nas formas de organização do trabalho. Nesse caso, além da continuidade da desigualdade de gênero nas empresas de conservas, os trabalhadores desconhecem formas participativas, formação de equipe, melhorias salariais e planos de carreira, ao mesmo tempo em que estão sendo familiarizados, por exemplo, com os discursos e técnicas de controle da "qualidade total" dos produtos e com as tecnologias automatizadas.

Outra questão colocada por Toledo (1997) é que, mesmo com todas as mudanças técnicas e organizacionais, não se percebe, em diferentes países da América Latina, uma alteração no perfil da força de trabalho quanto à condição de gênero, idade, qualificação e salário. Analisando uma pesquisa do início de 1990 (Vargas, 1994), nota-se que não houve alterações em relação ao perfil dos trabalhadores das conservas. Essa força de trabalho continua sendo predominantemente feminina, de baixa escolaridade, com trajetória de trabalho quase sempre em ocupações instáveis, condição de safrista como uma espécie de herança materna, moradia em bairros da periferia da cidade, presença da pobreza e uma forte marca da origem rural.

Se os trabalhadores das conservas, antes mesmo da onda de reestruturação produtiva, já conheciam situações de instabilidade e tratamento autoritário por parte das chefias, eles viram essas situações se intensificarem. Conforme Castro et al (1998), em

\footnotetext{
${ }^{17}$ No período da pesquisa, a safrista que acusou o chefe de estupro e o Sindicato dos Trabalhadores, estavam na justiça para comprovar o caso.
} 
toda América Latina ocorreu esse aumento do poder contratual da empresa, uma maior privatização das relações de trabalho em um contexto de intensa assimetria devido a fragmentação das instituições representativas dos trabalhadores. Nessa "reprivatização das relações de classe" (Cardoso, 2004, p. 109), o trabalho passa a ter um lugar cada vez mais subordinado nas relações de poder.

Nesses termos, e não no que se refere à tecnologia, é que o setor se tornou cada vez mais "arcaico", sem querer dizer com a expressão que, por isso, menos produtivo. Pelo contrário, a manutenção de formações retrógradas foi funcional a essa produtividade, indo ao encontro, assim, das afirmações de Fernandes (1967, p. 65), de que, no sistema capitalista, estruturas passadas adaptam-se e combinam-se às mudanças, velhas e novas configurações sociais imbricam-se a favor do capital.

No caso em análise, a tecnologia de ponta no ramo se articula com condições de trabalho que vão ao "limite da capacidade humana" (Fernandes, 1967). Trabalhadores submetidos à jornada de trabalho de até $19 \mathrm{~h}$, como a do caldeirista que afirma ser perigosa sua tarefa, "qualquer erro ali é fatal, não sobrevive ninguém" (Relato oral), e que mesmo assim não dorme o mínimo necessário à reposição dos sentidos vitais; os xingamentos e violências; o ritmo intenso; os acidentes; as práticas racistas; os problemas de Lesão por Esforços Repetitivos (LER); o barulho e o calor; a restrição de idas ao banheiro, enfim, todo esse cenário dramático que os trabalhadores relataram nas nossas entrevistas e denunciaram ao sindicato remete às formas mais retrógradas dos primórdios da industrialização.

A pesquisa de Vargas (1994), realizada no início de 1990, já registrava situações semelhantes. No que o estudo do autor parece distinguir do momento investigado é que, no início de 1990, ele podia concluir: "durante o período de safra, uma pessoa demitida pode conseguir emprego em outras empresas" (Vargas, 1994, p. 180). Essa possibilidade, para os trabalhadores entrevistados, parece estar bem menos colocada depois que as empresas mecanizaram as etapas mais intensivas do trabalho.

Se a tecnologia do descaroçamento, por exemplo, produz 350 pêssegos por minuto, inúmeras vezes mais do que se produzia na forma manual, aumentando, junto a outras técnicas, a capacidade produtiva, isso nada determinou para que a jornada de trabalho fosse reduzida, como gostariam, por exemplo, os sindicalistas. No setor conserveiro, as alterações tecnológicas em nada modificaram a "face arcaica do emprego da força de trabalho" (Iamamoto, 2001). Trata-se de um "desenvolvimento 
desigual" (Iamamoto, 2001, p. 174) que incorpora avanços da ciência e tecnologia, mantendo um padrão dilapidador de consumo da força de trabalho.

O excesso de trabalho que se verifica no setor lembra a afirmação de Marx quanto ao fato de que por si mesmas as tecnologias podem não alterar nada no que se refere ao excesso de trabalho. Marx diz: "se a maquinaria é o meio mais poderoso para aumentar a produtividade (...) em mãos do capital torna-se (...) o meio mais potente para prolongar a jornada de trabalho além de todos os limites estabelecidos pela natureza humana" (Marx, 1998, p. 459).

Frente a esse cenário, o sindicato que representa os trabalhadores das conservas se apresenta como crítico do despotismo empresarial. No entanto, segundo um sindicalista, "com as empresas que fecharam e com as que tão fechando, o sindicato reduziu muito a arrecadação, então não dá pra fazer muita coisa" (Vice-presidente do STICAP). Apesar desse retrocesso, nos últimos anos o STICAP fomentou várias mobilizações e greves no setor. Além disso, a partir dos anos 1990, começa a interagir mais com a esfera política governamental, atua junto a rádios comunitárias e cria o Grupo da LER, diversificando suas práticas. Observa-se, como analisa Ramalho (2006), que houve a necessidade de repensar a ação sindical, optando por participar de outras instâncias da vida política que afetam os trabalhadores. Num momento de debilidade sindical, o enfrentamento direto com os empresários do setor já não ocupa, na ação do sindicato, o lugar que ocupou quando havia muitas empresas e faltavam trabalhadores.

Em relação a sindicato e trabalhadores, o conservadorismo dos empresários do setor se expressa claramente por uma história de ameaças, de demissão de diretores sindicais, de repressão a greves com polícia e de violência direcionada àqueles que contestam a gestão do trabalho, como se viu, por exemplo, no relato de um trabalhador agredido fisicamente por um dos encarregados (Entrevista com safrista).

Diferente das argumentações psicologizantes que atribuem a tais empresários uma "mentalidade conservadora", entende-se que em relação às formas de produção são bastante "avançados", e que esse conservadorismo é próprio das formas como se relacionam com os trabalhadores. 


\section{Considerações finais}

No presente artigo, procurou-se entender a forma particular pela qual o setor conserveiro se integrou no movimento geral de reestruturação produtiva. Observou-se que, por mais que alguns interlocutores envolvidos nessa cadeia defendam a ideia de que tal segmento é conservador e pouco afeito a mudanças, a partir dos anos 1990 o ramo não esteve imune às transformações que atingiram diferentes setores produtivos durante a década.

Verificou-se que no segmento das conservas aconteceu uma forma muito específica de articulação entre as velhas e novas práticas. No interior e entre as empresas houve diferentes ritmos e intensidades na combinação desses pólos, ou seja, uma maneira mista de ser simultaneamente "tradicional e moderno".

Os trabalhadores que há anos se empregam no setor, sejam eles safristas ou efetivos, ao contrário daqueles que afirmam a estagnação dessa indústria, sentem de perto as transformações. Para esses, as mudanças são bastante vivas, em geral, atribuem a elas o maior desemprego na cidade e o fato, de hoje, terem que passar por situações vexatórias relacionadas ao comportamento autoritário da gerência, sem contar com a possibilidade de obter emprego em outra fábrica.

O sindicato, mais do que nunca, encontra dificuldades para se aproximar dos trabalhadores das conservas. As greves e mobilizações são menores do que lhes parece necessário em um ramo que incorpora de forma tão rudimentar os assalariados, guardando parentescos com os tempos pretéritos da Revolução Industrial.

Observou-se que as rudezas das condições enfrentadas pelos trabalhadores, os levam a travar uma série de conflitos envolvendo, principalmente, o controle do espaço/tempo no interior da produção.

Em suma, parcialmente, concluiu-se que houve no setor conserveiro uma reestruturação heterogênea no que se refere à Cadeia Produtiva, especialmente em relação às fábricas, enquanto no que diz respeito à dimensão do trabalho, uma intensificação da histórica precariedade das condições e relações de trabalho agravada pelo desemprego.

Embora com dificuldades de organização sindical, os trabalhadores não andam passivamente por esses processos, manifestam, muitas vezes, no próprio espaço de trabalho, suas rebeldias. 


\section{Referências Bibliográficas}

ABRAMO, Laís. Desafios atuais da sociologia do trabalho na América latina: Algumas hipóteses para discussão. In: Consejo latinoamericano de ciências sociales. México, 7-8 de outubro de 1999. Disponível em <http://www.clacso.org $>$

ANTUNES, Ricardo. A era da informatização e a época da informalização: Riqueza e miséria do trabalho. In: ANTUNES, Ricardo (org.). Riqueza e miséria do trabalho no Brasil. São Paulo: Boitempo, 2006.

BAUER, Martin, et al. A entrevista narrativa. In: BAUER, Martin; GASKELL, George (org.). Pesquisa qualitativa com texto: imagem e som: um manual prático. Petrópolis: Vozes, 2002.

BERNARDO, João. Democracia totalitária: teoria e prática da empresa. São Paulo: Cortez, 2004.

CARDOSO, Adalberto. A década neoliberal e a crise dos sindicatos no Brasil. São Paulo: Boitempo, 2004.

CASTRO, Nadya et al. Flexibilidade e precarização: os tempos mais duros. In: DEDECCA, Cláudio; CASTRO, Nadya (org.). Série II Congresso Latino-americano de sociologia do trabalho. A ocupação na América Latina: Tempos mais duros. São Paulo Rio de Janeiro: ALAST, 1998.

CATTANI, Antônio. Processo de trabalho e novas tecnologias: orientação para pesquisa e catálogo de obras. Porto Alegre: Editora da Universidade/UFRGS, 1995.

CORIAT, Benjamin. Pensar pelo avesso: o modelo japonês de trabalho e organização. Rio de Janeiro: Revan/UFRJ, 1994.

DECKER, Sérgio. Perfil, desempenho e capacidade tecnológica da agroindústria de doces e conservas da região sul do RS. Pelotas: EDUCAT, 2006.

FERNANDES, Florestan. Sociedade de classe e subdesenvolvimento. Rio de Janeiro: Zahar, 1967.

FERREIRA, Laura Senna. Reestruturação produtiva: mudanças e permanências no mundo do trabalho e empresarial da indústria conserveira na região de Pelotas-RS. 
Florianópolis: Programa de Pós Graduação em Sociologia Política/UFSC, 2008. (Dissertação de mestrado).

GARCIA, Ana Elisa. Mudança tecnológica e competitividade: a indústria de doces e conservas de frutas. São Paulo: Scortecci, 2002.

GERSICK, Kelin. et al. De geração para geração. Ciclos de vida da empresa familiar. São Paulo: Negócios, 1998.

GOMES, Maria. Empregabilidade nos tempos da reestruturação e flexibilização: Trajetórias de trabalho e narrativas de ex-empregados do setor elétrico brasileiro. Rio de Janeiro: Instituto de Filosofia e Ciências Sociais/UFRJ, 2002. (Tese de doutorado).

GRANDO, Marinês. Pequena agricultura em crise: o caso da "colônia francesa" no Rio Grande do Sul. Porto Alegre: Fundação de Economia e Estatística, 1989.

HARVEY, David. A condição pós-moderna. Uma pesquisa sobre as origens da mudança cultural. São Paulo: Loyola, 1992.

HIRATA, Helena. Entre mercado de trabalho, organização da produção e resistência dos trabalhadores: os meandros atuais da flexibilidade. In: Seminário internacional. Reestruturação produtiva, flexibilidade do trabalho e novas competências profissionais. Rio de Janeiro: COOPP/UFRJ, 1998a.

Reestruturação produtiva, trabalho e relações de gênero. Revista Latinoamericana de Estudios del Trabajo. Ano 4, n 7, $1998 \mathrm{~b}$.

IAMAMOTO, Marilda. Trabalho e indivíduo social: um estudo sobre a condição operária na agroindústria canavieira paulista. São Paulo: Cortez, 2001.

IANNI, Octavio. A era do globalismo. Rio de Janeiro: Civilização brasileira, 2004.

LEITE, Márcia. Tecendo a precarização: gênero, trabalho e emprego na indústria de confecções em São Paulo. In: SANTANA, Marco; RAMALHO, Ricardo (org.).

XXVIII ANPOCS. Trabalho, sindicato e os desafios do desenvolvimento. Caxambu: ANPOCS, 2004.

KIRSCHNER, Ana; SAINSAULIEU, Renaud. Sociologia da empresa: organização, poder, cultura e desenvolvimento no Brasil. Rio de janeiro: DP\&A, 2006. 
MARONI, Amnéris. A estratégia da recusa: análise das greves de maio de 78. São Paulo: Brasilense, 1982.

MARX, Karl. A lei geral da acumulação capitalista. In: MARX, Karl. O capital: Crítica da economia política: Livro I Vol. 2. 16 ed. Rio de Janeiro: Civilização brasileira, 1998. MATTOSO, Jorge. A desordem do trabalho. São Paulo: Página Aberta, 1995.

QUEIROZ, Maria. Relatos orais: Do “Indizível” ao "Dizível”. In: VON, Olga (org.). Experimentos com história de vida. São Paulo: Vértica, 1988.

RAMALHO, José Ricardo. Dinâmica sociopolíticas em novos territórios produtivos. In: RAMALHO, Ricardo (org.). Dossiê: Novos espaços industriais e desenvolvimento regional. Cadernos CRH. 19, n.46 - jan./abr. 2006.

SEBRAE. Diagnóstico da indústria de conservas do Estado do Rio Grande do Sul (Zona Sul). Porto Alegre, 1992.

SEBRAE. Avaliação de boas práticas de fabricação nas indústrias de conservas. Rio Grande do Sul: Agência de Promoção de Exportação (APEX), 1999.

SEBRAE. APL de conservas no pólo regional de Pelotas. Gestão do planejamento, orçamento e finanças - estudos e pesquisas. Rio Grande do Sul, 2006.

TAVARES, Jacqueline. A indústria conserveira pelotense: ascensão e declínio. Pelotas: UCPEL, 2000. (Dissertação de mestrado).

TOLEDO, Enrique. La flexibilidad del trabajo en América Latina. Revista Latinoamericana de Estudos do Trabalho. Ano 3, n5, 1997, pp.129-157.

TRAGTENBERG, Maurício. Burocracia e ideologia. São Paulo: Editora Ática, 1985.

VARGAS, Francisco. Relações sociais de classe e gênero: o trabalhador safrista na indústria de conservas de Pelotas. Porto Alegre: URGS, 1994. 